Check for updates

Cite this: J. Mater. Chem. A, 2021, 9 , 26810

\title{
Structural change induced by electrochemical sodium extraction from layered $\mathrm{O}^{\prime} 3-\mathrm{NaMnO}_{2} \dagger$
}

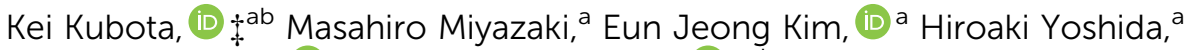 \\ Prabeer Barpanda (iD c and Shinichi Komaba (iD *ab
}

\begin{abstract}
Sodium-ion batteries can be designed as a low-cost alternative to lithium-ion batteries, where various layered transition metal oxides are frontrunner positive electrode materials. Owing to the inexpensive and abundant $\mathrm{Mn}$ resources and a large reversible capacity approaching $200 \mathrm{~mA} \mathrm{~h} \mathrm{~g}{ }^{-1}, \alpha$ type (O'3 type) $\mathrm{NaMnO}_{2}$ is considered as a competent and economical candidate for sodium-ion batteries. However, $\mathrm{O}^{\prime} 3 \mathrm{NaMnO}_{2}$ suffers from rapid capacity fading during charge-discharge cycling, for which the reasons remain elusive. The current work probes the underlying mechanisms behind this capacity degradation based on the correlation between the crystal structure and electrochemical properties. O'3 type $\mathrm{NaMnO}_{2}$, having a monoclinic O3-type structure, undergoes (de)intercalation of sodium ions through numerous potential plateaus and jumps corresponding to a number of intermediate phases. In situ and ex situ X-ray diffraction analyses reveal that the structure changes with different degrees of (de)sodiation and that eight different crystalline phases (co)exist. Furthermore, we have optimized the appropriate voltage window to achieve excellent cycling stability.
\end{abstract}

Received 26th June 2021

Accepted 7th November 2021

DOI: $10.1039 / \mathrm{d} 1 \mathrm{ta0} 390 \mathrm{f}$

rsc.li/materials-a

In fact, Na-ion chemistry was launched parallel to LIBs with

\section{Introduction}

Electrochemical energy storage devices, in particular Li-ion batteries (LIBs), have become ubiquitous in the 21st century, propelling myriads of consumers of electronic gadgets, electric vehicles and micro-to-mega grid storage. The consumption of lithium resources has leapt, and concern has been raised over its paucity with touting $\mathrm{Li}$ as the new gold. This scenario has renewed interest in Na-ion battery (NIB) chemistry which enables earth-abundant and low-cost alternative energy-storage devices to be achieved particularly if the target applications are not limited by the volumetric/gravimetric energy density. While many alternative alkali (earth) metal chemistries are being pursued (e.g. $\mathrm{K}, \mathrm{Mg}, \mathrm{Ca}, \mathrm{Al}$, etc.), NIBs have exhibited the most practically decent reversible capacity, rate kinetics, and thermal/chemical stability as well as safe storage and transportation..$^{\mathbf{1 - 4}}$

\footnotetext{
a Department of Applied Chemistry, Tokyo University of Science, 1-3 Kagurazaka, Shinjuku-ku, Tokyo 162-8601, Japan.E-mail: komaba@rs.tus.ac.jp

${ }^{b}$ Elements Strategy Initiative for Catalysts and Batteries (ESICB), Kyoto University, 130 Goryo-Ohara, Nishikyo-ku, Kyoto 615-8245, Japan

${ }^{c}$ Faraday Materials Laboratory, Materials Research Center, Indian Institute of Science, C.V. Raman Avenue, Bangalore, 560012, India

$\dagger$ Electronic supplementary information (ESI) available. See DOI: 10.1039/d1ta05390f

\$ Present address: Center for Green Research on Energy and Environmental Materials (GREEN), National Institute for Materials Science (NIMS), 1-1 Namiki, Tsukuba, Ibaraki 305-0044, Japan
} an early report on $\mathrm{Na}_{x} \mathrm{CoO}_{2}$ in $1980 .{ }^{1}$ With the prospects and commercialization of LIBs, the Na-ion story took a back seat. Recently, there has been a rapid revival of NIBs with suites of oxides and polyanionic insertion systems. While the polyanionic systems show the highest redox potential, the transition metal oxides deliver the highest reversible capacity. ${ }^{2}$ Various sodium layered transition metal oxides $\left(\mathrm{Na}_{x} \mathrm{TMO}_{2}\right.$, where $\mathrm{TM}=$ transition metal) and their solid-solutions have been intensively explored for feasible $\mathrm{Na}$ (de)intercalation. ${ }^{3-7}$ In contrast to $\mathrm{Li}$ layered oxides where $\mathrm{Li}^{+}$ions only occupy octahedral sites, $\mathrm{Na}_{x} \mathrm{TMO}_{2}$ accommodate $\mathrm{Na}^{+}$ions at prismatic or octahedral sites coordinated by six oxide ions. According to the notation proposed by Delmas and the type of coordination environment for $\mathrm{Na}^{+}$ions, $\mathrm{Na}_{x} \mathrm{TMO}_{2}$ is typically classified into P2, P3, and O3 type structures, depending on the polyhedral type of $\mathrm{Na}$ site and the number of $\mathrm{TMO}_{2}$ slabs in the hexagonal unit cell. ${ }^{8}$

Among these $\mathrm{Na}_{x} \mathrm{TMO}_{2}$, Mn-based compounds $\left(\mathrm{Na}_{x} \mathrm{MnO}_{2}\right)$ represent a promising family with cost-effective $\mathrm{Mn}$ as a result of its abundance and excellent energy density arising from high capacity. ${ }^{9-12}$ The stoichiometric composition of $\mathrm{NaMnO}_{2}$ crystallizes into two polymorphs: (i) a low-temperature monoclinic phase $\left(\alpha-\mathrm{NaMnO}_{2}\right)$ having a distorted O3 type structure (denoted as $\mathrm{O}^{\prime} 3$ type) owing to the lattice distortion arising from the Jahn-Teller effect of $\mathrm{Mn}^{3+}$ ions ${ }^{\mathbf{4 , 9 , 1 3}}$ and (ii) a high-temperature orthorhombic phase $\left(\beta-\mathrm{NaMnO}_{2}\right)$ with a corrugated-layer structure.,13-16 Nevertheless, DFT calculations estimate that the formation energies of these two phases are almost the 
same, ${ }^{\mathbf{1 6}}$ and it is known that it is experimentally difficult to synthesize a pure phase, especially a pure $\beta-\mathrm{NaMnO}_{2}$ phase. ${ }^{\mathbf{1 4}}$

The electrochemical performance of $\mathrm{O}^{\prime} 3$-type $\mathrm{NaMnO}_{2}$ was first probed as early as 1985 (ref. 9) and the first demonstration of efficient $\mathrm{Na}$ (de)intercalation was reported in 2011. ${ }^{4} \mathrm{O}^{\prime} 3-\mathrm{NaMnO}_{2}$ delivers a large reversible capacity approaching $200 \mathrm{~mA} \mathrm{~h} \mathrm{~g}{ }^{-1}$; however, it undergoes severe and continuous capacity loss upon cycling. ${ }^{4}$ Recently, Li et al. studied structural changes of $\mathrm{O}^{\prime} 3$-type $\mathrm{NaMnO}_{2}$ upon charging at the first cycle. ${ }^{17,18}$ They reported some intermediate phases having Na-vacancies and $\mathrm{Mn}^{\mathrm{III}}-\mathrm{Mn}^{\mathrm{IV}}$ orderings below $3.50 \mathrm{~V}$. Beyond this voltage, the $\mathrm{O} 1$ phase is developed and it tends to stay in a wide range upon the subsequent discharging process, leading to the asymmetric structural evolution. The activation process through the formation of the $\mathrm{O} 1$ phase in the high voltage region beyond $3.6 \mathrm{~V}$ was reported to be responsible for the improved cyclability. On the other hand, Ma et al. proposed the complete opposite. ${ }^{19}$ They reported that high voltage cycling induces structural degradation and capacity fading during cycling.

As part of our ongoing studies on understanding the chargedischarge mechanism and improvement of cyclability for $\mathrm{Na}_{x^{-}}$ $\mathrm{MnO}_{2}$ having high concentration of Jahn-Teller active $\mathrm{Mn}^{\mathrm{III}}{ }^{\mathbf{1 2 , 2 0}}$ it is of interest to investigate the relationship between the enigmatic structural changes in $\mathrm{O}^{\prime} 3-\mathrm{NaMnO}_{2}$ and its electrochemical properties (such as charge-discharge profile and cycling stability). In addition, the upper cut-off voltage is optimized to maximize the reversibility of $\mathrm{Na}$ extraction reactions and to improve the cycling performance of $\mathrm{O}^{\prime} 3-\mathrm{NaMnO}_{2}$. In the current work, the optimal voltage range of 2.0-3.476 V leads to enhanced cyclability. As a result, we have succeeded in identifying all crystalline phases and found that $\mathrm{O}^{\prime} 3-\mathrm{NaMnO}_{2}$ undergoes structural changes in seven crystalline phases with an $\mathrm{O}^{\prime} 3$ type structure up to $3.476 \mathrm{~V}$.

\section{Experimental}

\section{Synthetic procedures}

$\mathrm{NaMnO}_{2}$ was synthesized by a solid-state reaction. Reagent grade $\mathrm{Na}_{2} \mathrm{CO}_{3}$ (99.8\%, Kanto Chemical Co., Inc.), and $\mathrm{Mn}_{2} \mathrm{O}_{3}$ prepared by calcining $\mathrm{MnCO}_{3}$ (44\% as $\mathrm{Mn}$ content, Kishida Chemical Co., Ltd.) at $700{ }^{\circ} \mathrm{C}$ in air were mixed using a mortar and pestle. $3 \mathrm{~mol} \%$ excess amounts of $\mathrm{Na}_{2} \mathrm{CO}_{3}$ were used in consideration of the high volatility of sodium oxides during the heat treatment. The mixture was pelletized and was calcined in a muffle furnace at $800{ }^{\circ} \mathrm{C}$ for $10 \mathrm{~h}$ in air at a heating rate of $5{ }^{\circ} \mathrm{C} \mathrm{min}^{-1}$. In addition, lower temperature or longer heattreatment samples were prepared by heating at $700{ }^{\circ} \mathrm{C}$ for $24 \mathrm{~h}$ and at $800{ }^{\circ} \mathrm{C}$ for $48 \mathrm{~h}$. Only for the case of the low temperature heating at $700{ }^{\circ} \mathrm{C}$, the starting materials were ballmilled for $12 \mathrm{~h}$ at $600 \mathrm{rpm}$ before the calcination. The calcined products were quenched by taking them out from the heated furnace and were quickly transferred into an Ar-filled glovebox. The quenched samples were cooled to room temperature inside the glovebox so as to avoid any moisture contamination and/or unwanted oxidation. It led to the formation of the desired $\mathrm{O}^{\prime} 3$ $\mathrm{NaMnO}_{2}$ product, which was used for structural and electrochemical characterization.

\section{Structural and morphological characterization}

The structure of the as-synthesized $\mathrm{O}^{\prime} 3-\mathrm{NaMnO}_{2}$ was examined by X-ray diffraction (XRD) measurements using a laboratoryscale X-ray diffractometer (MultiFlex, Rigaku Corporation) equipped with a $\mathrm{Cu} \mathrm{K} \alpha \mathrm{X}$-ray source with a Ni filter (operating at $40 \mathrm{kV} / 30 \mathrm{~mA}$ ). A homemade air-tight sample holder was used for the XRD measurements to avoid sample exposure to air. Detailed structures of the as-synthesized and electrochemically tested samples were determined with a synchrotron X-ray diffractometer at BL02B2 of SPring-8 in Japan, equipped with a large Debye-Scherrer camera. For ex situ measurements, the samples were prepared electrochemically by holding the targeted voltage for sufficient time (typically $60 \mathrm{~h} ; 24 \mathrm{~h}$ only in the case of cycling 10 times) after galvanostatic charging at $12 \mathrm{~mA} \mathrm{~g}^{-1}$ using a coin type cell to ensure electrode equilibrium. Constitution of the coin type cell is described in the next section. The composite electrodes were taken out from the coin cell as soon as possible after the voltage holding process or after $30 \mathrm{~h}$ only in the case of cycling 10 times without the $2.0 \mathrm{~V}$ holding. The electrodes were washed by dipping them several times in dimethyl carbonate (DMC, Kishida Chemical Co., Ltd.) to remove any electrolyte salt, and then dried overnight at room temperature in an Ar-filled glovebox. For ex situ laboratory-scale XRD measurements, the rinsed and dried composite electrodes were used, but for ex situ synchrotron XRD measurements, the oxide composites were separated from the aluminum current collectors and crushed into powders.

The as-synthesized and electrochemically tested samples were put into glass capillaries, 0.3 and $0.5 \mathrm{~mm}$ in diameter, respectively. The glass capillaries were sealed with a resin in the glovebox or by heating and melting the end of glass capillaries to eliminate sample exposure to air. To minimize the effect of $\mathrm{X}$ ray absorption by the samples, the wavelength of the incident $\mathrm{X}$ ray beam was set to $0.5 \AA$ using a silicon monochromator and was calibrated with NIST standard reference material (SRM) $674 \mathrm{~b} \mathrm{CeO}_{2}$ as an external standard reference. Structural parameters were refined by the Rietveld method with the program RIETAN-FP. ${ }^{21}$ XRD patterns were also simulated by the RIETAN-FP program and compared to the observed patterns. Schematic illustrations of crystal structures were drawn using the VESTA program..$^{22}$ Structural changes of $\mathrm{O}^{\prime} 3-\mathrm{NaMnO}_{2}$ during an initial charging process were examined by an operando XRD technique using a battery-cell attachment (Rigaku Corporation) and the data were collected using the above-mentioned X-ray diffractometer. Particle morphology was observed using a scanning electron microscope (SEM, JCM-6000, JEOL Ltd.) operating at an acceleration voltage of $15 \mathrm{kV}$.

\section{Electrochemical characterization}

Composite electrodes were prepared by making a slurry containing $80 \mathrm{wt} \%$ active material, $10 \mathrm{wt} \%$ acetylene black (AB, Strem Chemicals, Inc.), and $10 \mathrm{wt} \%$ poly(vinylidene fluoride) (PVdF, Polysciences, Inc.) binder in an adequate amount of $\mathrm{N}$ methylpyrrolidone (NMP, Kanto Chemical Co., Inc.). This slurry was coated on an $\mathrm{Al}$ foil and was dried at $80{ }^{\circ} \mathrm{C}$ under vacuum. The electrode sheet was punched into a disk shape to make 
a working electrode. The mass loading of the active material was $\sim 3 \mathrm{mg} \mathrm{cm}^{-2}$. The working electrode was incorporated into R2032 coin cells with a glass fiber separator (BG-100R, Advantec Co.) soaked with electrolyte $\left(1 \mathrm{~mol} \mathrm{dm}{ }^{-3} \mathrm{NaPF}_{6}\right.$ in propylene carbonate, Kishida Chemical Co., Ltd.) and Na metal (purity > 99\%, Kanto Chemical Co., Inc.) as a counter/reference electrode. Electrochemical tests were performed at $25{ }^{\circ} \mathrm{C}$ using a charge-discharge measurement system (TOSCAT-3100, TOYO System Co., Ltd.), in various voltage ranges, primarily at a current rate of $\mathrm{C} / 20\left(\mathrm{ca} .12 \mathrm{~mA} \mathrm{~g}^{-1}\right)$. The galvanostatic intermittent titration technique (GITT) was carried out with charging at a $\mathrm{C} / 50$ rate (ca. $4.8 \mathrm{~mA} \mathrm{~g}^{-1}$ ) for one hour and resting for 30 hours at $25{ }^{\circ} \mathrm{C}$. Except for operando XRD and GITT, constant current and constant voltage (CC-CV) mode was employed for the charging process or both charging and discharging processes.

\section{Results and discussion}

\section{Structural analysis of the as-synthesized $\mathrm{O}^{\prime} 3-\mathrm{NaMnO}_{2}$}

A fitted profile of the synchrotron XRD pattern for the assynthesized $\mathrm{O}^{\prime} 3-\mathrm{NaMnO}_{2}$ is shown in Fig. 1a, and the refined structural parameters are summarized in Table S1 in the ESI. $\dagger$ Almost all Bragg diffraction peaks can be indexed to an $\mathrm{O}^{\prime} 3$ type structure (the prime on $\mathrm{O}$ represents a distorted lattice from a hexagonal one) with a space group (S.G.) of $\mathrm{C} 2 / \mathrm{m}$, where $\mathrm{Na}^{+}$ ions occupy octahedral sites in the interslab space between $\mathrm{MnO}_{2}$ slabs stacked along the $c$-axis with ABCABC oxygen stacking arrays, and the number of $\mathrm{MnO}_{2}$ slabs in a pseudohexagonal unit cell is three (Fig. 1b). The ratio of lattice parameter $b / a$ for the monoclinic $\mathrm{O}^{\prime} 3-\mathrm{NaMnO}_{2}$ is 1.98 , which is higher than the $\sqrt{3}$ obtained for the hexagonal system. Furthermore, two $\mathrm{Mn}-\mathrm{O}$ bonds in a $\mathrm{MnO}_{6}$ octahedron are longer than the other four bonds as shown in Fig. 1b. These
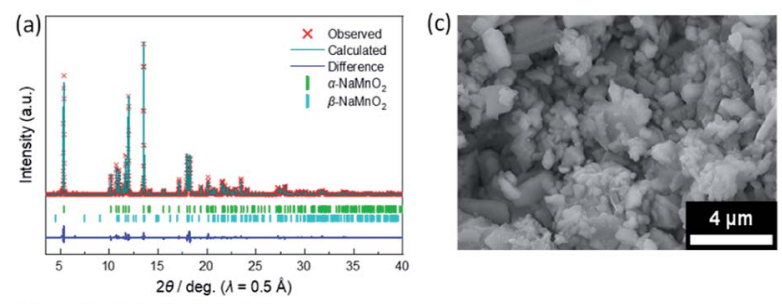

(b)

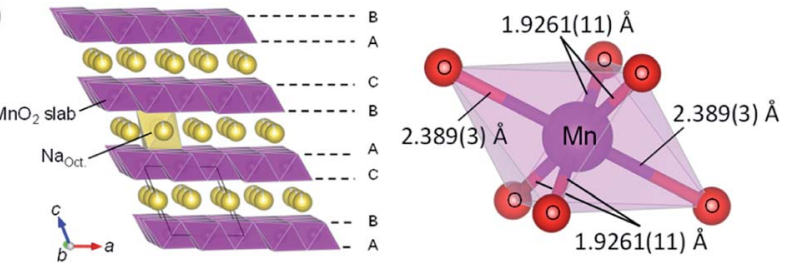

Fig. 1 (a) Rietveld refinement results of the synchrotron XRD pattern for $\mathrm{O}^{\prime} 3-\mathrm{NaMnO}_{2}$. Observed data points are shown in red with the fitted profile shown in olive. Green and blue-green tick marks indicate allowed reflections for the $\mathrm{O}^{\prime} 3$ type ( $\alpha$ type) phase (S.G. C2/m) and the $\beta$ type phase (S.G. Pmmn), respectively. (b) Schematic illustrations of the refined layered structure of the $\mathrm{O}^{\prime} 3$ phase (left) and $\mathrm{MnO}_{6}$ octahedron in the refined structure (right). (c) SEM image of the assynthesized $\mathrm{O}^{\prime} 3-\mathrm{NaMnO}_{2}$ results are consistent with previous reports ${ }^{17,23}$ and confirm cooperative Jahn-Teller distortion associated with $\mathrm{Mn}^{3+}$ ions. Although a trace amount of $\beta$ type phase was detected on the synchrotron XRD pattern, the refined mass fraction was as low as $4.6 \%$, and an almost single phase of $\mathrm{O}^{\prime} 3-\mathrm{NaMnO}_{2}$ is successfully synthesized. The morphology of the as-prepared $\mathrm{O}^{\prime} 3-\mathrm{NaMnO}_{2}$ exhibits primary particles ranging from 200 to $500 \mathrm{~nm}$, which agglomerate to form micrometric secondary particles ranging from 1 to $4 \mu \mathrm{m}$ (Fig. 1c).

\section{Effect of upper cut-off voltages on electrochemical properties}

Using the synthesized $\mathrm{O}^{\prime} 3-\mathrm{NaMnO}_{2}$ as a positive electrode active-material, a charge-discharge test of a non-aqueous $\mathrm{Na}$ cell was carried out in the voltage range of 2.0-3.8 $\mathrm{V}$ at a current density of $12 \mathrm{~mA} \mathrm{~g}^{-1}\left(\mathrm{C} / 20,1 \mathrm{C}=244 \mathrm{~mA} \mathrm{~h} \mathrm{~g}^{-1}\right)$ as shown in Fig. 2. At the end of the first charge, almost $0.9 \mathrm{Na}$ per formula unit is successfully extracted, delivering an initial charge capacity of $c a .215 \mathrm{~mA} \mathrm{~h} \mathrm{~g}^{-1}$. The characteristic stepwise voltage profile is clearly observed on the first charge, which is related to the various Na-vacancy orderings, ${ }^{17,18}$ whereas the stepwise profile is largely absent upon discharge (Fig. 2a). Despite a high initial discharge capacity of $c a .180 \mathrm{~mA} \mathrm{~h} \mathrm{~g}{ }^{-1}$, its capacity gradually fades upon cycling, retaining 58\% (104 $\left.\mathrm{mA} \mathrm{h} \mathrm{g}^{-1}\right)$ at the $50^{\text {th }}$ cycle (Fig. 2b). In addition, the various plateaus on charge become unclear in the course of cycling, in agreement with previous reports. ${ }^{\mathbf{4 , 1 8 , 1 9 , 2 3}}$

In order to determine the appropriate upper cut-off voltages, quasi-equilibrium voltages were examined through GITT with charging at $\mathrm{C} / 50\left(\mathrm{ca} .4 .8 \mathrm{~mA} \mathrm{~g}^{-1}\right)$ initially for $1 \mathrm{~h}$ and then for $0.5 \mathrm{~h}$ followed by resting for $30 \mathrm{~h}$ as shown in Fig. 3. Seven distinct voltage plateaus are observed upon desodiation with average voltage values of $2.54,2.70,2.76,2.94,3.10,3.45$, and $3.52 \mathrm{~V}$. All the voltage plateaus correspond to the two-phase reactions associated with phase transitions upon $\mathrm{Na}$ extraction. The detailed structural changes are discussed in a later section. The long plateau observed at the lowest voltage of $2.54 \mathrm{~V}$ and short plateaus at 2.76 and $3.10 \mathrm{~V}$ have relatively small polarization (ca. $0.05 \mathrm{~V}$ ) but it is slightly larger than that of the other two plateaus at 2.70 and $2.94 \mathrm{~V}$ in the low voltage region (Fig. 3b). In contrast, much larger polarization develops above $3.10 \mathrm{~V}$ where the Na content is smaller than 0.4 , probably due to sluggish phase transformation, limited Na kinetics in the corresponding phases, and/or undesired structural deterioration.
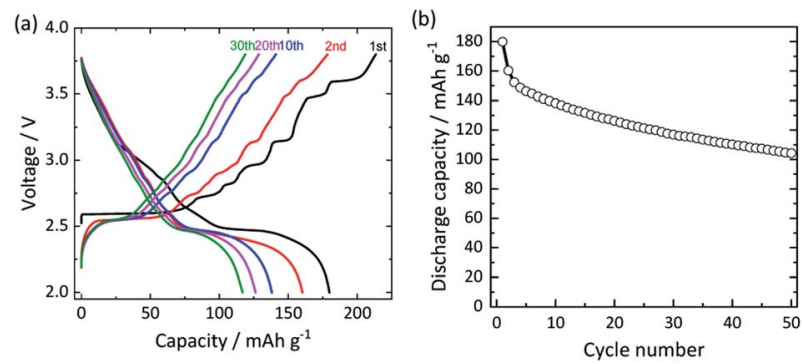

Fig. 2 (a) Charge-discharge curves of the $\mathrm{O}^{\prime} 3-\mathrm{NaMnO}_{2}$ electrode in a $\mathrm{Na}$ cell cycled in $\mathrm{CC}-\mathrm{CV}$ mode at $12 \mathrm{~mA} \mathrm{~g}^{-1}$ in the voltage range of 2.0-3.8 $\mathrm{V}$ at $25^{\circ} \mathrm{C}$ and (b) cycling stability over 50 cycles. 

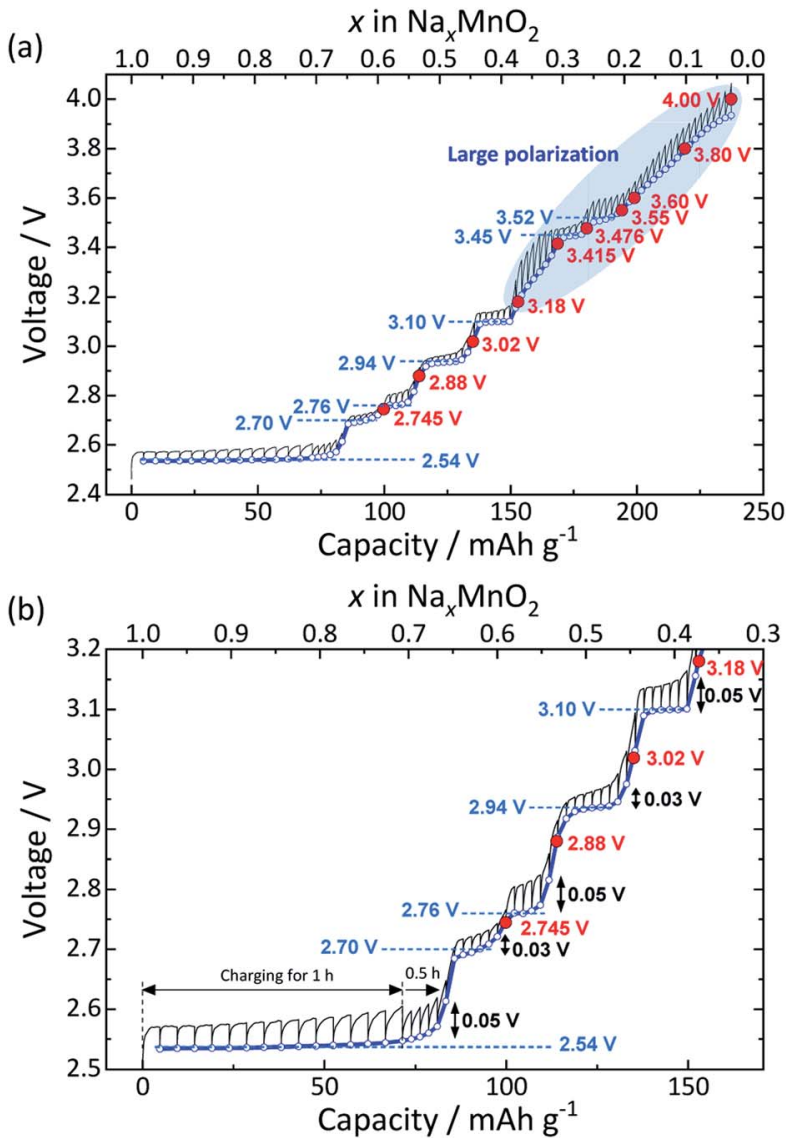

Fig. 3 (a) GITT curves obtained by charging at $4.8 \mathrm{~mA} \mathrm{~g}^{-1}$ for $1 \mathrm{~h}$ or $0.5 \mathrm{~h}$ followed by relaxation for $30 \mathrm{~h}$. The blue line and circles represent the open circuit voltage plots obtained from GITT. Selected upper cut-off voltages for cycling tests in $\mathrm{CC}-\mathrm{CV}$ mode are highlighted in red circles. (b) Magnified curves of panel (a) between 2.5 and $3.2 \mathrm{~V}$.

One of the strategies to mitigate capacity fade is optimization of an upper cut-off voltage as experienced in $\mathrm{Na}$ layered oxides with a single TM. ${ }^{24,25}$ To address this, we selected a total of ten voltages as upper cut-off voltages based on the intermediate voltage between two successive plateaus except for the initial low-voltage plateau, plus the several higher voltages (indicated by the red circles in Fig. 3a). In order to ensure accuracy in the electrochemical measurement, cells were cycled under a CC-CV mode in the charging process, where the cells were galvanostatically charged at $12 \mathrm{~mA} \mathrm{~g}^{-1}$ up to each cut-off voltage and then the cell voltage was held for $12 \mathrm{~h}$.

During the discharge process to $2.0 \mathrm{~V}$, a constant current (CC) mode was employed without voltage holding. Fig. 4a shows the comparative initial charge-discharge curves of $\mathrm{O}^{\prime} 3-\mathrm{NaMnO}_{2}$ electrodes during charging to the various upper cut-off voltages ranging from 2.745 to $4.000 \mathrm{~V}$. The distinct voltage plateaus are unambiguous in both charge and discharge profiles when cells were charged up to the upper cut-off voltage lower than $3.55 \mathrm{~V}$. In contrast, charging to higher voltages (i.e. 3.60, 3.80, and 4.00 $\mathrm{V})$ gives sloping voltage profiles followed by only one plateau at ca. $2.45 \mathrm{~V}$ on discharge. This is further illustrated by the comparative differential capacity versus voltage $(\mathrm{d} Q / \mathrm{d} V)$ plots
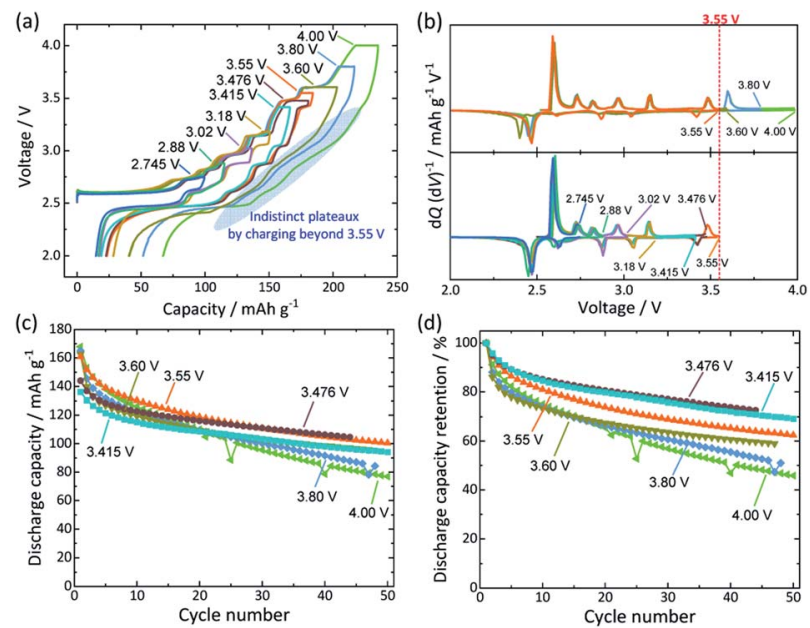

Fig. 4 (a) Initial charge-discharge curves of the $\mathrm{O}^{\prime} 3-\mathrm{NaMnO}_{2}$ electrode in $\mathrm{Na}$ cells cycled in $\mathrm{CC}-\mathrm{CV}$ mode with charging to different upper cut-off voltages with $12 \mathrm{~h}$ holding at the voltages and discharging to $2.0 \mathrm{~V}$ at $25{ }^{\circ} \mathrm{C}$. (b) The corresponding $\mathrm{d} Q / \mathrm{dV}$ plots for the cells charged to voltages higher (top) and lower (bottom) than $3.55 \mathrm{~V}$. (c) Discharge capacity and (d) the retention rate over 45 cycles.

(Fig. $4 \mathrm{~b}$ and c). When the upper cut-off voltage is limited to $3.55 \mathrm{~V}$ or lower, almost all redox peaks corresponding to the voltage plateaus are distinct and reversible during charging and discharging, but this is not the case for higher cut-off voltages above $3.55 \mathrm{~V}$, suggesting that irreversible electrochemical reactions occur when the voltage exceeds $3.55 \mathrm{~V}$.

Given that the highest upper cut-off voltage for greater reversibility of redox voltage plateaus is determined to be $3.55 \mathrm{~V}$, cycling performance of the $\mathrm{O}^{\prime} 3-\mathrm{NaMnO}_{2}$ electrode was examined under charging to the selected upper cut-off voltages (see chargedischarge curves obtained for all upper cut-off voltages in Fig. S1†). As shown in Fig. 4c, the highest capacity is delivered for the first 25 cycles when the upper cut-off voltage is $3.55 \mathrm{~V}$. On the other hand, when the capacity retention is compared in Fig. 4d, raising the upper cut-off voltage from 3.476 to $4.000 \mathrm{~V}$ results in more severe capacity decay during cycling. Considering the initial capacity and capacity retention, an optimal voltage range for $\mathrm{O}^{\prime} 3-\mathrm{NaMnO}_{2}$ is proposed to be $2.0-3.476 \mathrm{~V}$ in a non-aqueous Na cell.

It is worth noting that lower upper cut-off voltages below $3.4 \mathrm{~V}$ also result in lower cycle retention during cycling (Fig. S1 $\dagger$ ). Furthermore, when the CC-CV mode is additionally employed for the discharging process, the capacity retention in the optimal voltage range of 2.0-3.476 $\mathrm{V}$ becomes worse compared to that without the voltage holding on discharging (Fig. S2†). These results imply side reactions such as irreversible surface reactions with electrolyte in the low voltage regions as reported for $\mathrm{P} 2-\mathrm{Na}_{x} \mathrm{Co}_{2 / 3} \mathrm{Mn}_{2 / 9} \mathrm{Ni}_{1 / 9} \mathrm{O}_{2} \cdot{ }^{26}$ Indeed, addition of $0.5 \mathrm{wt} \%$ fluoroethylene carbonate (FEC) to electrolyte as an electrolyte additive ${ }^{27}$ significantly improves cycling stability, and no distinct capacity fading is confirmed during cycling in the 2.0-3.02 $\mathrm{V}$ range (see Fig. S3†).

On the other hand, in the optimal voltage range of 2.0$3.476 \mathrm{~V}$, no significant influence of the FEC addition is 
confirmed in Fig. S3. $\uparrow$ To improve cycling stability and understand the capacity decay mechanism, $\mathrm{O}^{\prime} 3-\mathrm{NaMnO}_{2}$ with larger or smaller particles was prepared under different heattreatment conditions. The electrodes of the larger or smaller $\mathrm{O}^{\prime} 3-\mathrm{NaMnO}_{2}$ particles demonstrate almost the same or slightly worse capacity retention (Fig. $\mathrm{S} 4 \dagger$ ). Interestingly, the smaller particle size of $\mathrm{O}^{\prime} 3-\mathrm{NaMnO}_{2}$ more or less maintains the stepwise profiles of charge-discharge curves and delays the irreversible change in profiles into sloping ones during cycling compared to the larger particle size. This implies that structural changes during $\mathrm{Na}$ extraction from $\mathrm{O}^{\prime} 3-\mathrm{NaMnO}_{2}$ induce internal stress in the bulk as reported for $\mathrm{O}^{\prime} 3-\mathrm{NaNiO}_{2} \cdot{ }^{28}$ Consequently, capacity fading would be related not only to the irreversible surface reactions but also to the internal stress generated by structural changes in the bulk. The irreversible and gradual change in the charge-discharge profiles during cycling is associated with the crystallite size and bulk structure rather than surface reactions, which agrees with the recent report by Amine and co-workers. ${ }^{19}$

\section{Ex situ structural analysis in the charging process}

In the GITT curves in Fig. 3, seven distinct voltage plateaus are confirmed during the initial charging as mentioned above. Such a flat voltage plateau principally corresponds to a two-phase reaction of a structural change. After the voltage plateau region during charging, the formation of a single phase is expected at the end of the plateaus, i.e., the voltage jump regions such as $2.63 \mathrm{~V}, 2.745 \mathrm{~V}, 2.88 \mathrm{~V}, 3.00 \mathrm{~V}, 3.25 \mathrm{~V}, 3.476 \mathrm{~V}$, and $3.58 \mathrm{~V}$, as highlighted in yellow in Fig. S5. $\dagger$ With the addition of the as-synthesized $\mathrm{O}^{\prime} 3$ type phase, a total of eight phases are expected to exist in $\mathrm{Na}_{x} \mathrm{MnO}_{2}$ during the $\mathrm{Na}$ extraction process. However, the structure of more than half of the phases has not yet been elucidated. Here, in order to clarify the undetermined structure and to elucidate its relationship with capacity degradation during charge-discharge cycles, we first investigated the structural changes of $\mathrm{NaMnO}_{2}$ by ex situ synchrotron XRD. The measured points are summarized in the open circuit voltage (OCV) plots in Fig. $55 . \dagger$

Fig. 5 displays a series of ex situ synchrotron XRD patterns of the $\mathrm{NaMnO}_{2}$ electrodes charged to the targeted voltages. As expected, we succeeded in detecting eight major phases in the patterns from pristine to the electrode charged to $3.80 \mathrm{~V}$. Diffraction peaks of the main phase can be indexed to the $\mathrm{O}^{\prime} 3$ type structure except for the diffraction peaks of the eighth phase observed in the electrodes charged to 3.58 and $3.80 \mathrm{~V}$. Therefore, we numbered and labeled the phases in order from the initial low voltage phase to the high voltage phase in sequence as $\mathrm{O}^{\prime} 3(1)$ to $\mathrm{O}^{\prime} 3(7)$, where $\mathrm{O}^{\prime} 3(1)$ is the as-synthesized $\mathrm{NaMnO}_{2}$. The seven phases of the $\mathrm{O}^{\prime} 3$ type are highly crystalline, but the eighth phase is less crystalline and was assigned to an $\mathrm{O}^{\prime} 3$-O1-like phase (denoted as $\mathrm{O}^{\prime} 3-\mathrm{O} 1(8)$ in this study) as proposed by Chen et al. ${ }^{18}$ These phases are also detected by laboratory-scale XRD, but low intensity superlattice peaks are not observed as shown in Fig. S6. $\dagger$ On the other hand, as reported by Chen et al., ${ }^{18}$ superlattice reflections of the $\mathrm{O}^{\prime} 3(2)$, $\mathrm{O}^{\prime} 3(4)$, and $\mathrm{O}^{\prime} 3(6)$ phases are confirmed in the synchrotron XRD patterns of the charged electrode samples at 2.63, 2.88, and
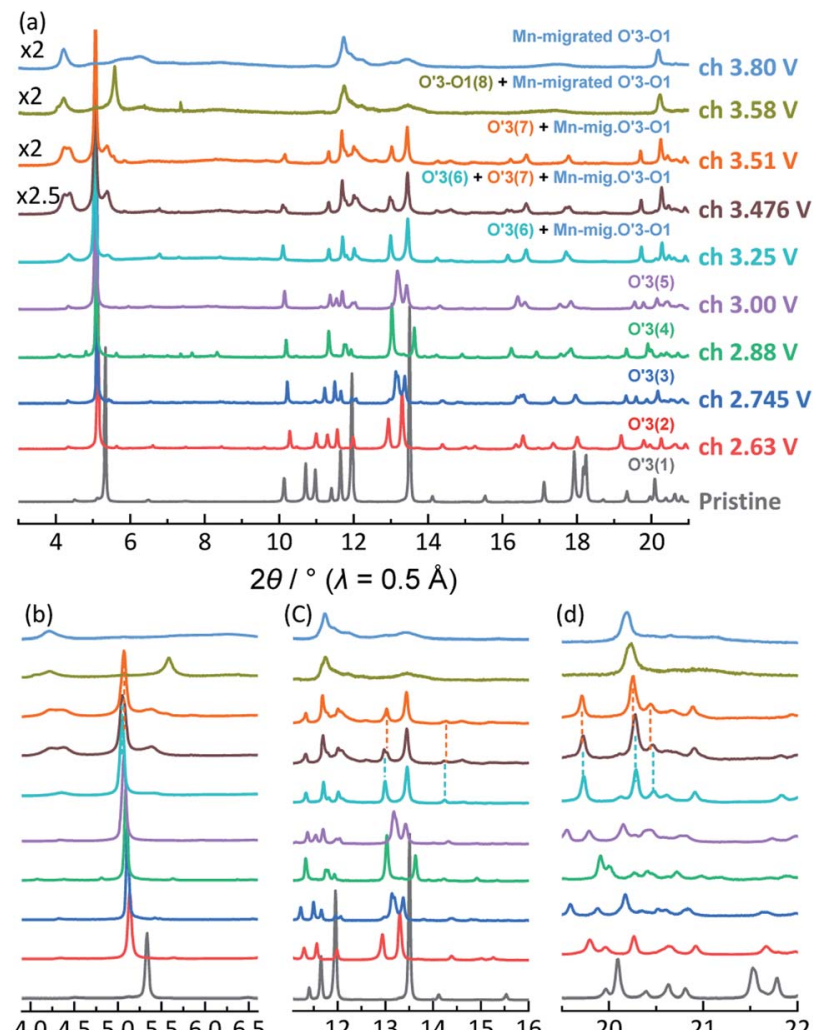

(C) $\wedge$
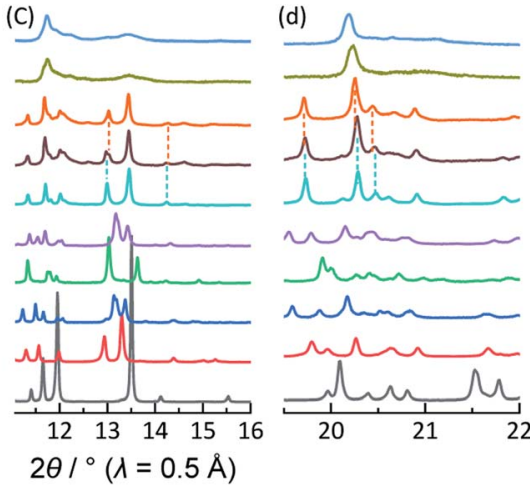

Fig. 5 Ex situ synchrotron XRD patterns collected at the selected states of charge: (a) wide diffraction angle range, (b) $3.9^{\circ} \leq 2 \theta \leq 6.6^{\circ}$, (c) $11.1^{\circ} \leq 2 \theta \leq 16.0^{\circ}$, and (d) $19.5^{\circ} \leq 2 \theta \leq 22.0^{\circ}$. The intensity in panel (d) is twice those in the other panels.

3.25 $\mathrm{V}$, respectively, suggesting Na-vacancy ordering due to $\mathrm{Mn}^{\mathrm{III}}-\mathrm{Mn}^{\mathrm{IV}}$ ordering or related interactions. Rietveld refinements on the XRD patterns for the three samples reveal small $R$ factors (see the refinement results in Tables S2-S4†) and good agreement between the observed and calculated patterns as shown in Fig. S7-S9. $\dagger$ The refined structures are illustrated in Fig. 6. Different from a previous report, ${ }^{18} \mathrm{O}^{\prime} 3(4)$ and $\mathrm{O}^{\prime} 3(6)$ are found to have $a \times 4 b \times c$ (S.G. $P 2 / c)$ and $a \times 3 b \times c$ (S.G. $C 2 / m$ ) supercells, respectively. The structures of all three phases exhibit in-plane Na-vacancy ordering and $\mathrm{Mn}^{\mathrm{III}}-\mathrm{Mn}^{\mathrm{IV}}$ ordering as predicted by DFT calculations. ${ }^{\mathbf{1 8 2 9 , 3 0}}$ Although the charge disproportionation may not be complete and the electrons may not be completely localized at room temperature, the refined $\mathrm{Mn}-\mathrm{O}$ bond length and bond valence sum (BVS) imply the $\mathrm{Mn}^{\mathrm{III}}-\mathrm{Mn}^{\mathrm{IV}}$ ordering. The polarization of the flat voltage plateaus at $2.63,2.88$, and $3.25 \mathrm{~V}$ is indeed large and gradually increases during charging (Fig. 3b). This may be related to the formation of the three phases with partly localized electrons that lower the electronic conductivity of the oxide.

On the other hand, $\mathrm{O}^{\prime} 3(3), \mathrm{O}^{\prime} 3(5)$, and $\mathrm{O}^{\prime}(7)$ phases have not been reported yet. When compared in detail, the reflection position of the $\mathrm{O}^{\prime} 3(7)$ phase is very close to that of the $\mathrm{O}^{\prime} 3(6)$ phase as shown in Fig. 5b-d. The reflections of the $\mathrm{O}^{\prime} 3(7)$ phase can be indexed to a typical monoclinic model with an $a \times b \times c$ cell and a space group of $C 2 / \mathrm{m}$. However, the reflections of the 
(a)

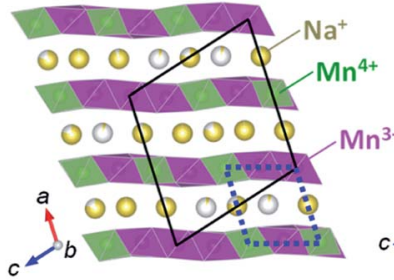

(b)

(c)

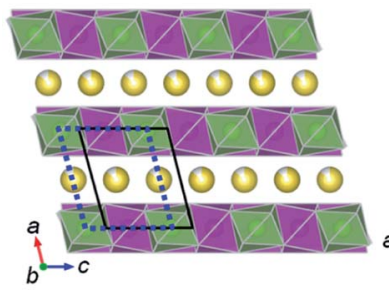

(e)

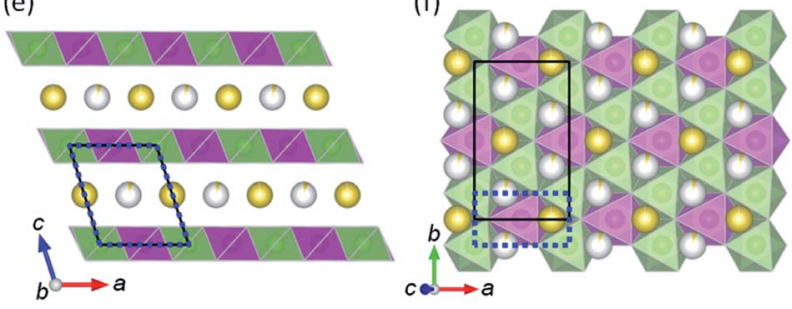

Fig. 6 Schematic illustrations of crystal structures of $\mathrm{Na}_{x} \mathrm{MnO}_{2}$ obtained by Rietveld refinements of the synchrotron XRD patterns for the electrodes charged to $(a, b) 2.63 \mathrm{~V}$, (c, d) $2.88 \mathrm{~V}$, and (e, f) $3.25 \mathrm{~V}:(\mathrm{a}, \mathrm{c}, \mathrm{e})$ stacking and $(b, d, f)$ in-plane structures. The main phase of the electrodes corresponds to $\mathrm{O}^{\prime} 3(2), \mathrm{O}^{\prime} 3(4)$, and $\mathrm{O}^{\prime} 3(6)$, respectively. The solid black squares represent unit cells, and the dashed blue squares represent primitive unit cells as a reference.

$\mathrm{O}^{\prime} 3(3)$ and $\mathrm{O}^{\prime} 3(5)$ phases cannot be indexed to a monoclinic cell but can be indexed to a triclinic cell. Based on a typical monoclinic $a \times b \times c$ cell model, we refined the structural parameters of the triclinic $\mathrm{O}^{\prime} 3(3)$ and $\mathrm{O}^{\prime} 3(5)$ phases by a Rietveld method as shown in Fig. S10 and S11 and Tables S5 and S6. $\dagger$ Indeed, lattice parameters $\alpha$ and $\gamma$ are slightly different from $90^{\circ}$, and simulation reproduces split reflections of $h 1 l$ and $h \overline{1} l$ (see Fig. S12†), evidencing the triclinic structures.

Finally, with the observed pattern of the eighth phase, we compared the simulation pattern of the $\mathrm{O} 1$ type structure as shown in Fig. S13† according to Chen's report. ${ }^{18}$ However, the XRD pattern simulation of the O1 type structure does not reproduce the observed pattern. Instead, simulation of the O6 type structure, which is an intermediate between $\mathrm{O} 3$ and $\mathrm{O} 1$ types (Fig. S13a $\dagger$ ), reproduces the observed peak position (Fig. S13b $\dagger$ ). Considering the broad reflections of $10 l$ and $01 l$, stacking faults would be formed between $\mathrm{O} 3$ and $\mathrm{O} 1$ types as O3-O1. Since the seventh phase is distorted into a monoclinic $\mathrm{O}^{\prime} 3$ type, the eighth phase would be an $\mathrm{O}^{\prime} 3-\mathrm{O} 1$ (or $\mathrm{O}^{\prime} 3-\mathrm{O}^{\prime} 1$ ) phase. The peak intensity of $113_{\mathrm{O} 3}$ (or $116_{\mathrm{O} 6}$ or $111_{\mathrm{O} 1}$ ) at a diffraction angle of $2 \theta=21^{\circ}$ is indeed lower than that of the simulation, indicating that the peak is split due to the monoclinic system having lower symmetry than the hexagonal (or rhombohedral) system. It is also possible that manganese ions migrated from the $\mathrm{MnO}_{2}$ slab to the $\mathrm{Na}$ site in the interslab space, as reported by Ma et al. ${ }^{19}$ and this may explain the low intensity peak as shown in the simulated patterns in Fig. S13c. $\dagger$ However, since the intensity of the $00 l$ reflection decreases due to the migration of manganese, the number of migrated manganese ions is small in the $\mathrm{O}^{\prime} 3-\mathrm{O} 1(8)$ phase in the electrode charged to $3.58 \mathrm{~V}$. Rather than the $3.58 \mathrm{~V}$ electrode, the phase in the $3.80 \mathrm{~V}$ electrode is estimated to have more migrated manganese ions in the interslab space based on the lower intensity of the $00 \mathrm{l}$ and $113_{\mathrm{O} 3}$ (or $116_{\mathrm{O} 6}$ or $111_{\mathrm{O} 1}$ ) reflections (Fig. S13c $\dagger$ ), and this phase is hereinafter called Mn-migrated O'3-O1(9). Since typical $\mathrm{MnO}_{2}$ polymorphs of pyrolusite ( $\beta$ (rutile-type) $\left.\mathrm{MnO}_{2}\right)$, nsutite $\left(\gamma-\mathrm{MnO}_{2}\right)$, and ramsdellite $\left(\mathrm{R}-\mathrm{MnO}_{2}\right)$ have $1 \times 1$ or $2 \times 1$ tunnels with O1-like oxygen stacking, Mn migration from the slabs to the interslab space might become more energetically favorable in the almost Na-free 01 type structure as O1-type $\mathrm{MnO}_{2}$ with $50 \% \mathrm{Mn}$ that randomly migrated into the interslab space has been reported to be akhtenskite $\left(\varepsilon-\mathrm{MnO}_{2}\right) \cdot{ }^{31}$ The lab-scale XRD patterns in Fig. S6b $\dagger$ also showed a gradual decrease in the intensity of the $00 l$ reflection at $17.2^{\circ}$ during charging, confirming the gradual disappearance of the $\mathrm{O}^{\prime} 3-\mathrm{O} 1(8)$ phase without peak shift.

\section{Operando structural analysis in the charging process}

Based on the above-mentioned phase identification with ex situ synchrotron XRD, operando XRD and phase assignment were conducted. Fig. 7 shows a contour profile map for the operando XRD patterns upon the first charging at $6 \mathrm{~mA} \mathrm{~g}^{-1}$. As represented by grey dashed lines, seven $\mathrm{O}^{\prime} 3$ type and one $\mathrm{O}^{\prime} 3-\mathrm{O} 1$ type single-phase (or solid-solution) regions are confirmed. Careful perusal of the contour plot reveals that, upon charging, novel diffraction peaks appear on all the voltage plateau regions, while the original diffraction peaks remain without peak shift but are weakened. It clearly indicates phase evolution via two-

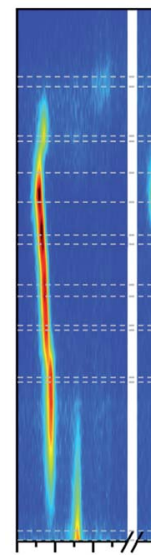

151617

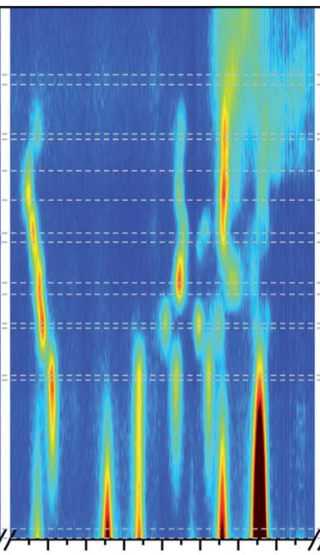

$\begin{array}{lllllll}32 & 33 & 34 & 35 & 36 & 37 & 38\end{array}$ $2 \theta /$ deg. (CuKa)

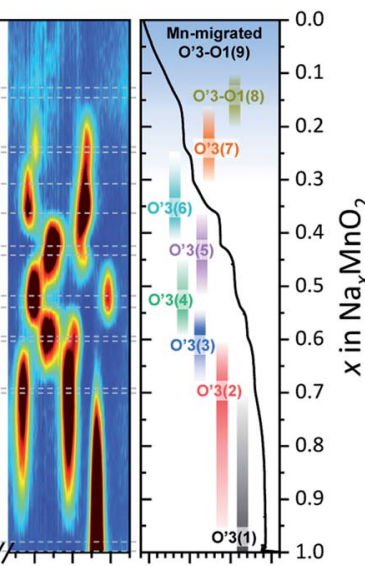

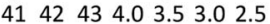
Voltage / V
Fig. 7 Contour profile map of operando XRD patterns during galvanostatic charging at $6 \mathrm{~mA} \mathrm{~g}^{-1}$ at the first cycle. Grey dashed lines are a guide for the eye, representing the appearance of seven single-phase regions. The simultaneously collected voltage curve as a function of sodium content $x$ in $\mathrm{Na}_{x} \mathrm{MnO}_{2}$ is shown on the right side. Background intensity and the diffraction peaks from an $\mathrm{Al}$-coated $\mathrm{Be}$ window and $\mathrm{Al}$ current collector were subtracted. 
phase reactions. In the first plateau around $2.6 \mathrm{~V}, \mathrm{O}^{\prime} 3(2)$ gradually increases at the expense of $\mathrm{O}^{\prime} 3(1)$, undergoing complete phase transition from $\mathrm{O}^{\prime} 3(1)$ to $\mathrm{O}^{\prime} 3(2)$. A similar two-phase transition process continues with progressive charging to $3.8 \mathrm{~V}$, involving seven $\mathrm{O}^{\prime} 3$ phases and one $\mathrm{O}^{\prime} 3-\mathrm{O} 1$ phase determined by ex situ synchrotron XRD (Fig. 5). The operando analyses reveal multiple phase transitions from $\mathrm{O}^{\prime} 3(1)$ to $\mathrm{O}^{\prime} 3-1(8)$, involving seven biphasic regions separated by monophasic endmembers. The crystalline monoclinic $\mathrm{O}^{\prime} 3$ structure indeed degrades above $3.55 \mathrm{~V}$, but a low-crystalline phase of $\mathrm{O}^{\prime} 3-\mathrm{O} 1(8)$ is confirmed in the operando XRD patterns and the operando synchrotron XRD data reported by Chen et al. ${ }^{18}$ In the structural evolution, unlike in Ma's report, ${ }^{19} \mathrm{O}^{\prime} 3-\mathrm{NaMnO}_{2}$ does not transform into $\mathrm{P} 3$ or $\mathrm{P}^{\prime} 3$ type phases. Nevertheless, P3 type materials are synthesized by solid-state reactions as $\mathrm{P} 3-\mathrm{Na}_{x}-$ $\mathrm{MnO}_{2}$ in the $\mathrm{Mn}$ system ${ }^{32,33}$ and are usually observed in the phase evolution during the charging of $\mathrm{O} 3$ and $\mathrm{O}^{\prime} 3$ type $\mathrm{NaTMO}_{2}$ such as $\mathrm{NaCrO}_{2},{ }^{25} \mathrm{NaCoO}_{2},{ }^{1} \mathrm{NaNiO}_{2},{ }^{34}$ and $\mathrm{NaNi}_{1 /}$ ${ }_{2} \mathrm{Mn}_{1 / 2} \mathrm{O}_{2} \cdot{ }^{35,36}$ Indeed, variation of the in-plane Mn-to-Mn distance is unusual and partly similar to the $\mathrm{O}^{\prime} 3-\mathrm{P}^{\prime} 3$ transition as discussed in detail below.

Lattice parameters of basic $a \times b \times c$ unit cells were calculated from the operando XRD data to further investigate the changes in crystal structure with multiple phase transitions. Further, the variations in interslab distance and in-plane MnMn distance were calculated from the lattice parameters and are depicted in Fig. 8a and b, respectively. Note that the in-plane $\mathrm{Mn}-\mathrm{Mn}$ distance of the $\mathrm{O}^{\prime} 3-\mathrm{O} 1(8)$ phase could not be calculated because the 110 and $10 l$ peaks overlap with the $\mathrm{Al}$ peaks and are too broad and weak. Considering the triclinic phase, the averaged interslab distance corresponds to the length of the reciprocal lattice vector $c,\left|c^{*}\right|$ (Fig. 8c), and is obtained using the following equation:
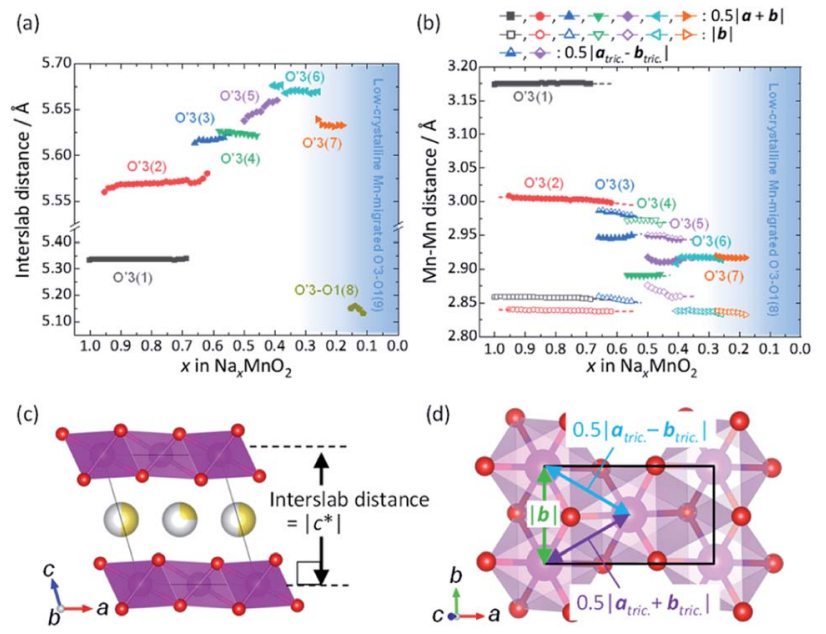

Fig. 8 Refinement results exhibiting the changes in (a) interslab distance and (b) in-plane $M n-M n$ distance. Schematic illustrations for (c) interslab and (d) in-plane $\mathrm{Mn}-\mathrm{Mn}$ distances in a structure. The $\mathrm{Mn}-$ $\mathrm{Mn}$ distance of the $\mathrm{O}^{\prime} 3-\mathrm{O} 1(8)$ phase could not be calculated because the 110 and 10 l peaks overlap with the Al peaks and are too broad and weak.

$$
\left|\boldsymbol{c}^{*}\right|=\frac{V}{|\boldsymbol{a}| \times|\boldsymbol{b}| \times \sin \gamma}
$$

On the other hand, in-plane $\mathrm{Mn}-\mathrm{Mn}$ distances in the averaged structure correspond to $|\boldsymbol{b}|, 0.5|\boldsymbol{a}+\boldsymbol{b}|$, and $0.5|\boldsymbol{a}-\boldsymbol{b}|$ values as shown in Fig. 8d. The monoclinic structure has two types of in-plane Mn-Mn distance $(|\boldsymbol{b}|$ and $0.5|\boldsymbol{a}+\boldsymbol{b}|$ (equal to 0.5 $\mid \boldsymbol{a}-$ $\boldsymbol{b} \mid$ )), while the triclinic structure has three types. With progressive Na extraction, electrostatic repulsion between the adjacent $\mathrm{MnO}_{2}$ slabs is enlarged, resulting in increasing the interslab distance. This increasing trend in the interslab distance continues throughout the desodiation process until the $\mathrm{O}^{\prime} 3(7)$ phase emerges. The decreased interslab distance of the $\mathrm{O}^{\prime} 3(7)$ phase appearing at around $3.50 \mathrm{~V}$ is consistent with those in previous studies ${ }^{\mathbf{1 8 , 1 9}}$ despite different phase determination from the present study. Furthermore, during the phase transition from $\mathrm{O}^{\prime} 3(7)$ to $\mathrm{O}^{\prime} 3-\mathrm{O} 1(8)$ at a voltage plateau of $c a$. $3.6 \mathrm{~V}$, the interslab distance decreases from $5.63 \AA$ to $5.15 \AA$. The interlayer distance of $\mathrm{O}^{\prime} 3-\mathrm{O} 1(8)$ is very close to the $5.1 \AA$ reported based on operando synchrotron XRD measurements, ${ }^{18}$ which is consistent with our lab-scale operando XRD measurement in this study. On the other hand, variation of the in-plane Mn-Mn distance is very complicated. In general, the in-plane TM-TM distance decreases by oxidation of transition metal ions and weakened in-plane repulsion of $\mathrm{Na}^{+}-\mathrm{Na}^{+}$in the interslab space by extraction of large $\mathrm{Na}^{+}$ions upon charging. One can see a discrete and significant variation of the in-plane $\mathrm{Mn}-\mathrm{Mn}$ distance in Fig. 8b, and several features are found. First, the variation of the in-plane $\mathrm{Mn}-\mathrm{Mn}$ distance (3.17 to $2.84 \AA$ ) is significantly larger than that of the TM-TM distances for typical $\mathrm{NaTMO}_{2}$ such as $\mathrm{NaCrO}_{2}$ (2.98 to $2.88 \AA$ ) ${ }^{25} \mathrm{NaFe}_{1 / 2} \mathrm{Co}_{1 / 2} \mathrm{O}_{2}(2.95$ to $2.81 \AA$ ),${ }^{37}$ and $\mathrm{NaNi}_{1 / 2} \mathrm{Mn}_{1 / 2} \mathrm{O}_{2}$ (2.97 to $2.84 \AA$ ). ${ }^{36}$ Of course, the variation range of the TM-TM distances is highly dependent on the voltage range (i.e., Na extraction range), but the initial value of $\mathrm{O}^{\prime} 3-\mathrm{NaMnO}_{2}(3.17 \AA)$ is quite large even compared to those of other $\mathrm{O}^{\prime} 3$ types such as $\mathrm{NaNiO}_{2}(3.02 \AA) .{ }^{34}$ The large initial value leads to the result that one of the Mn-Mn distances (i.e., 0.5 $\mid \boldsymbol{a}+$ $\boldsymbol{b} \mid$ ) is significantly different between $\mathrm{O}^{\prime} 3(1)$ and $\mathrm{O}^{\prime} 3(2)$. Second, during the phase evolution with a two-phase reaction, at least one $\mathrm{Mn}-\mathrm{Mn}$ distance is almost the same between the two phases, which is similar to the trend observed in $\mathrm{NaNi}_{1 / 2} \mathrm{Mn}_{1 /}$ ${ }_{2} \mathrm{O}_{2} \cdot{ }^{36}$ Third, the trend of long Mn-Mn distance $0.5|\boldsymbol{a}+\boldsymbol{b}|$ and short Mn-Mn distance $|\boldsymbol{b}|$ in the monoclinic structures of $\mathrm{O}^{\prime} 3(1$, 2,6 , and 7) phases is reversed only in that of the $\mathrm{O}^{\prime} 3(4)$ phase. In other words, in the $\mathrm{O}^{\prime} 3(4)$ phase, Mn-Mn distance $0.5|\boldsymbol{a}+\boldsymbol{b}|$ is short and $\mathrm{Mn}-\mathrm{Mn}$ distance $|\boldsymbol{b}|$ is long. Such reversal is found for the $\mathrm{O}^{\prime} 3-\mathrm{P}^{\prime} 3$ transition in $\mathrm{NaNi}_{1 / 2} \mathrm{Mn}_{1 / 2} \mathrm{O}_{2} \cdot{ }^{36}$ Fourth, the two triclinic phases, $\mathrm{O}^{\prime} 3(3)$ and $\mathrm{O}^{\prime} 3(5)$, appear to complement the difference in $\mathrm{Mn}-\mathrm{Mn}$ distance between the two phases $\mathrm{O}^{\prime} 3(2)$ and $\mathrm{O}^{\prime} 3(4)$, and between the two phases $\mathrm{O}^{\prime} 3(4)$ and $\mathrm{O}^{\prime} 3(6)$.

\section{Ex situ structural analysis in the discharging process}

From the operando and ex situ XRD data, structural changes during the initial charging process are elucidated, but those during the discharge process are still unclear. Considering the very low intensity of diffraction peaks after charging beyond the 

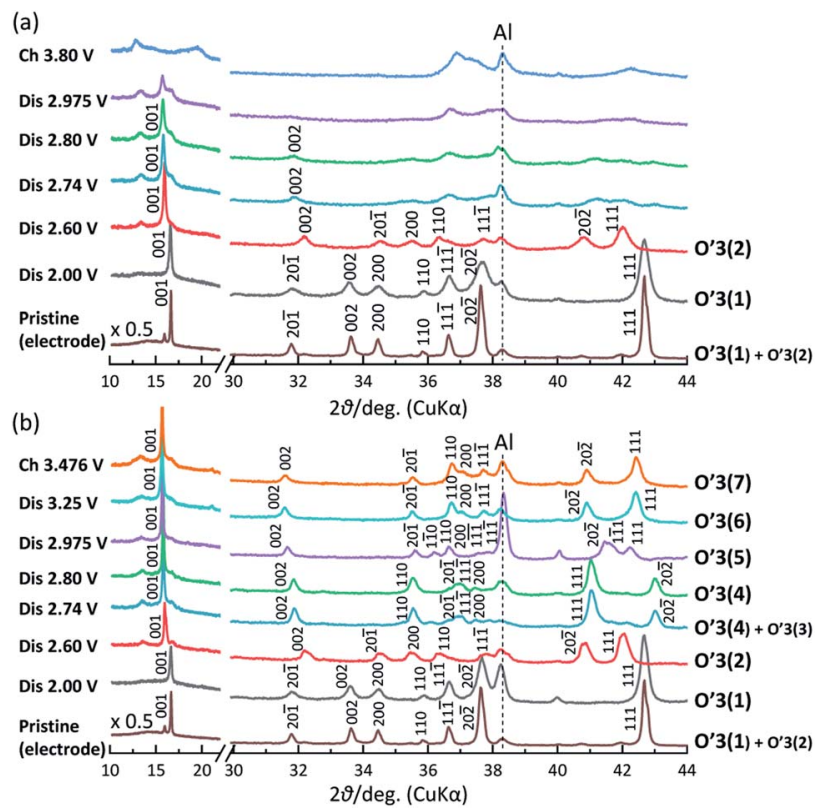

Fig. 9 Ex situ laboratory-scale XRD patterns of the electrodes discharged from (a) $3.80 \mathrm{~V}$ and (b) $3.476 \mathrm{~V}$ to the selected voltages with voltage holding for $60 \mathrm{~h}$. During the charge process, the voltage was held for $12 \mathrm{~h}$ after galvanostatic charging at $12 \mathrm{~mA} \mathrm{~g}^{-1}$.

plateau of 3.50-3.55 V, ex situ XRD measurements were performed instead of operando XRD on the electrode samples discharged from $3.476 \mathrm{~V}$ or $3.80 \mathrm{~V}$ (Fig. 9). In order to ensure a uniform sample in the equilibrium state, a constant voltage was applied for $60 \mathrm{~h}$ after discharging to the desired voltage.

As expected from the asymmetric redox reactions between charging and discharging (Fig. 4b), the electrodes discharged from $3.80 \mathrm{~V}$ show very broad diffraction peaks up to $2.74 \mathrm{~V}$, except for the 001 reflection at $2 \theta=15.8^{\circ}$, and sharp peaks of $\mathrm{O}^{\prime} 3(2)$ and $\mathrm{O}^{\prime} 3(1)$ are observed at 2.60 and $2.00 \mathrm{~V}$, respectively, in Fig. 9a, which agrees with the appearance of only the $2.45 \mathrm{~V}$ reduction peak corresponding to the transition from $\mathrm{O}^{\prime} 3(2)$ to $\mathrm{O}^{\prime} 3$ (1) (Fig. 4b). In contrast, the electrodes discharged from $3.476 \mathrm{~V}$ show sharp diffraction peaks, and six $\mathrm{O}^{\prime} 3$ type phases are detected in the reverse process although the peak intensity of the $\mathrm{O}^{\prime} 3(3)$ phase is very low. The reduction peak originating from the transition from $\mathrm{O}^{\prime} 3(4)$ to $\mathrm{O}^{\prime} 3(3)$ is indeed not clearly seen in the 2.87-2.61 $\mathrm{V}$ range in Fig. $4 \mathrm{~b}$.

All the ex situ XRD results for the discharging process are consistent with the results of the charge and discharge curves. The remarkable recovery of crystallinity and the formation of $\mathrm{O}^{\prime} 3(2)$ during discharge from $3.8 \mathrm{~V}$ are also consistent with the results observed in the reported operando synchrotron XRD. ${ }^{18}$ The 2.0 V electrode discharged from $3.8 \mathrm{~V}$ shows broader diffraction peaks than those in the electrode discharged from $3.476 \mathrm{~V}$. However, the difference in peak width is too small to explain the different cycling stabilities.

Interestingly, broad peaks surrounding the 001 reflection are observed at $2 \theta=13.0^{\circ}-13.3^{\circ}(d=6.65-6.80 \AA)$ and $2 \theta=16.7^{\circ}(d$ $=5.30 \AA$ ) up to the formation of $\mathrm{O}^{\prime} 3(1)$ as shown in Fig. 9, and at least the lower-angle peak does not originate from the wide interslab space of hydrates, which is proved by the synchrotron XRD data of hydrates in Fig. S14. $\dagger$ In the synchrotron XRD pattern of the $3.8 \mathrm{~V}$ electrode (Fig. S13b $\dagger$ ), the low-angle peak at $2 \theta=4.21^{\circ}(d=6.80 \AA)$ can be assigned to the 200 reflection with a $3 a \times b \times c$ supercell. Although accurate values of lattice constants and crystal symmetry of the high-voltage phase were difficult to determine due to too broad and weak peaks, the roughly calculated lattice constants $(a=13.6 \AA, b=2.85 \AA$, and $c$ $=4.5 \AA)$ are close to those of $\gamma-\mathrm{MnO}_{2}(a=13.7 \AA, b=2.87 \AA, c=$ $4.46 \AA$, and $\left.\beta=90.5^{\circ}\right)^{38}$ (Fig. S13c $\dagger$ ). $\gamma-\mathrm{MnO}_{2}$ has pyrolusite $(\beta$ $\left.\mathrm{MnO}_{2}\right)$ type and ramsdellite $\left(\mathrm{R}-\mathrm{MnO}_{2}\right)$ type portions in the structure, ${ }^{38}$ which is a modulated structure and is different from the Mn-migrated O1-type structure (50\% of the Mn-migrated O1 type is $\left.\varepsilon-\mathrm{MnO}_{2}\right)$. Chen et al. also reported the presence of $\mathrm{O}^{\prime} 3$ like and O1-like domains alternately formed (stacked along the $\langle 201\rangle$ direction) as striped regions based on the TEM images. ${ }^{18}$ Furthermore, the low-angle broad peak at $2 \theta=4.21^{\circ}(d=6.80 \AA)$ is also observed after drying the hydrate to remove the interslab water (see Fig. S14b $\dagger$ ). Thus, the appearance of broad superstructure peaks can be explained by the migration of Mn into the interslab space to form a modulated phase and/or the coexistence of differently oriented domains. This broad peak may be a good indicator to understand the long-range structural degradation.

\section{Cycling effect on crystallinity}

In addition to the observation of the broad-peak phase, various phase transitions with significant changes in the in-plane $\mathrm{Mn}-\mathrm{Mn}$ distance during charging and the formation of a low-crystalline $\mathrm{O}^{\prime} 3-\mathrm{O} 1(8)$ phase on the $3.52 \mathrm{~V}$ plateau at the open-circuit voltage $(\mathrm{Na}<0.2)$ suggest that not only local structural changes such as formation of stacking faults and $\mathrm{Mn}$ migration, but also the accumulation of lattice stress through phase transitions eventually leads to capacity degradation. In order to confirm the speculation, ex situ XRD measurements were carried out for the electrode samples after initial charging and discharging and cycling in the two different voltage ranges of 2.0-3.476 $\mathrm{V}$ and 2.0$3.80 \mathrm{~V}$.

First, changes in charge-discharge profiles are compared as differential curves as shown in Fig. 10. All oxidation and reduction peaks become less intense over cycling regardless of voltage ranges. Interestingly, the oxidation peak at the lowest voltage shifts notably towards lower voltage after charging to $3.8 \mathrm{~V}$ and continues to move during cycling, implying a pronounced change in the local $\mathrm{Mn}-\mathrm{O}$ coordination environment upon the first charging to $3.80 \mathrm{~V}$. An analogous phenomenon also occurs even in the narrower voltage range of 2.0-3.476 V; however, a gradual voltage decay is observed with the appearance of an oxidation peak at $2.55 \mathrm{~V}$ from the $5^{\text {th }}$ cycle accompanied by decreasing intensity of the oxidation peak at $2.58 \mathrm{~V}$. This may indicate that the local Mn coordination changes slowly during cycling in the $2.0-3.476 \mathrm{~V}$ range, whereas it changes rapidly when charging above $3.476 \mathrm{~V}$ up to $3.8 \mathrm{~V}$.

Fig. 11 displays the ex situ XRD patterns after 10 cycles in different voltage ranges of 2.0-3.80 $\mathrm{V}$ and 2.0-3.476 V. In order to clarify the phases just after the conventional cycling test, we 


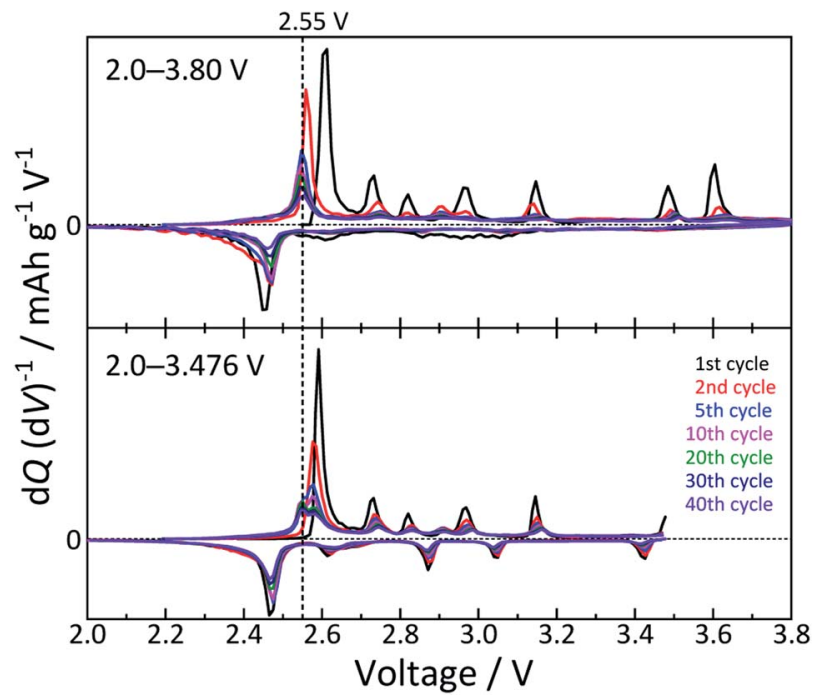

Fig. $10 \mathrm{~d} Q / \mathrm{d} V$ plots for $\mathrm{O}^{\prime} 3-\mathrm{NaMnO}_{2}$ electrodes cycled at $12 \mathrm{~mA} \mathrm{~g}^{-1}$ under $\mathrm{CC}-\mathrm{CV}$ mode (only on charging) in the different voltage ranges of 2.0-3.80 V (top) and 2.0-3.476 V (bottom).

did not perform CCCV discharge in the final cycle but cycled the sample under the same conditions as the cycling test in Fig. 4. It is obvious that diffraction peaks such as $11 \overline{3}$ and 202/311 reflections become broader with raising the upper cut-off voltage as well as increasing the number of cycles. This presumably suggests a decrease in crystallinity (suppressed long-range ordering), such as trapped migrated $\mathrm{Mn}$ in the interslab space and formation of stacking faults, which are analogous to a previous study. ${ }^{19}$ It is true that the peak is broadened when the $\mathrm{O}^{\prime} 3-\mathrm{O} 1(8)$ phase and the Mn-migrated $\mathrm{O}^{\prime} 3$ O1(9) phase are generated by charging to a high voltage (Fig. 9 and 11), but a broad peak ( $2 \theta=4.2^{\circ}$ to $4.5^{\circ}$ in Fig. 5$)$ is generated even when charging to $3.25 \mathrm{~V}$ or higher. By applying the $\mathrm{CV}$ treatment at the end of the $10^{\text {th }}$ cycle, the $13^{\circ}$ broad peak weakened and the $\mathrm{O}^{\prime} 3(2)$ phase peak disappeared (Fig. 11b), but

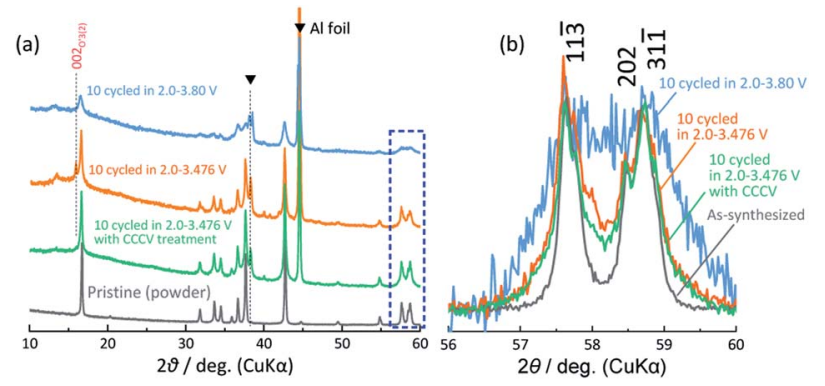

Fig. 11 (a) Ex situ XRD patterns of the electrodes after the 10 cycles at $12 \mathrm{~mA} \mathrm{~g}^{-1}$ under CC-CV mode (only on charging) in the different voltage ranges of $2.0-3.476 \mathrm{~V}$ (orange) and $2.0-3.80 \mathrm{~V}$ (light blue). The pattern of the sample where the constant voltage treatment $(2.0 \mathrm{~V}$ holding for $24 \mathrm{~h}$ ) is also applied to the $10^{\text {th }}$ discharging process of $2.0-$ $3.476 \mathrm{~V}$ cycling is also shown in green. (b) The magnified XRD patterns in the region for 113 and 202/311 reflections (blue dashed square in panel ' $a$ '). The XRD pattern of the as-synthesized $\mathrm{O}^{\prime} 3-\mathrm{NaMnO}_{2}$ powder is also presented as a reference. there was no noticeable change in the peak profile of $11 \overline{3}$ and 202/31个 reflections (especially the peak width). This suggests that the modulation and defect phases, which show the lowangle broad peak, may disrupt the long-range order, and even if the modulation and defect phases disappear, the crystallinity of the $\mathrm{O}^{\prime} 3$ phase is no longer recovered.

Actually, avoiding the formation of low-crystallinity $\mathrm{O}^{\prime} 3$ O1(8) and Mn-migrated phases, i.e., cycling below $3.476 \mathrm{~V}$, is critical for the long cycle life of $\mathrm{O}^{\prime} 3-\mathrm{NaMnO}_{2}$. The phase evolution of $\mathrm{O}^{\prime} 3-\mathrm{Na}_{x} \mathrm{MnO}_{2}$ is kinetically slow and is related to the crystallite size of the as-synthesized $\mathrm{O}^{\prime} 3-\mathrm{NaMnO}_{2}$. The $\mathrm{O}^{\prime} 3-$ $\mathrm{NaMnO}_{2}$ sample has a structural part of $\beta-\mathrm{NaMnO}_{2}$ as a planar defect in the $\mathrm{O}^{\prime} 3-\mathrm{NaMnO}_{2}$ particle ${ }^{14}$ as well as long-range ordered crystalline $\beta-\mathrm{NaMnO}_{2}$ domains (see the structural refinement results in Fig. 1a). Smaller particle but more highly crystalline $\mathrm{O}^{\prime} 3-\mathrm{NaMnO}_{2}$ is expected to demonstrate rapid phase transitions and better cycling stability as a positive electrode material for NIBs. Furthermore, Na-extracted $\mathrm{O}^{\prime} 3-\mathrm{NaMnO}_{2}$ always has distorted $\mathrm{MnO}_{6}$ octahedra with a monoclinic or triclinic lattice symmetry, and is expected to exhibit specific magnetic and anion-redox behaviors.

\section{Conclusions}

The electrochemical performance of an $\mathrm{O}^{\prime} 3-\mathrm{NaMnO}_{2}$ electrode has been systematically examined in a non-aqueous $\mathrm{Na}$ cell by changing the upper cut-off voltage. The optimum voltage window is $2.0-3.476 \mathrm{~V}$, showing fully reversible multiple voltage plateaus. Synergizing ex situ synchrotron XRD and operando XRD analyses, the underlying phase evolution mechanism is found to proceed through six distinct two-phase reactions involving seven distinct $\mathrm{O}^{\prime} 3$ phases during charging up to $3.476 \mathrm{~V}$. Further charging beyond the $3.52 \mathrm{~V}$ plateau at the open-circuit voltage leads not only to the formation of a low-crystalline $\mathrm{O}^{\prime} 3-\mathrm{O} 1$ phase and $\mathrm{Mn}$ migrated phases but also to the asymmetric discharge profile. The phase transition associated with this decrease in crystallinity results in the formation of $\mathrm{O}^{\prime} 3$ phases with low crystallinity even in the discharged state, resulting in severe capacity degradation during cycling in the wider voltage range. When operated in a suitable voltage range, highly crystalline $\mathrm{O}^{\prime} 3-\mathrm{NaMnO}_{2}$ can be an economical candidate for rechargeable NIBs with formidable energy density and long cycle life.

\section{Author contributions}

M. Miyazaki and H. Yoshida conducted the materials synthesis and the structural and electrochemical characterization. K. Kubota and M. Miyazaki analyzed the experimental data. K. Kubota, E. J. Kim, and P. Barpanda prepared the manuscript. S. Komaba supervised the project and co-wrote the manuscript. All the authors discussed the results and contributed to writing the manuscript.

\section{Conflicts of interest}

There are no conflicts to declare. 


\section{Acknowledgements}

This study was in part supported by the Japan Science and Technology Agency (JST) through the Adaptable and Seamless Technology Transfer Program through Target driven R\&D (ASTEP), Project No. AS2614056L and through the CONCERTJapan program of the Strategic International Research Cooperative Program (SICORP), Grant No. JPMJSC17C1 and by the Element Strategy Initiative of the Ministry of Education Culture, Sports, Science and Technology, Japan (MEXT), Grant Number JPMXP0112101003. The synchrotron X-ray diffraction experiments were performed at the BL02B2 and BL19B2 beamlines of SPring-8 with the approval of JASRI (Proposal No. 2014B1820 and 2015A1881). PB acknowledges Tokyo University of Science for a visiting fellowship during summer 2016.

\section{References}

1 J.-J. Braconnier, C. Delmas, C. Fouassier and P. Hagenmuller, Mater. Res. Bull., 1980, 15, 1797-1804.

2 N. Yabuuchi, K. Kubota, M. Dahbi and S. Komaba, Chem. Rev., 2014, 114, 11636-11682.

3 J. Zhao, L. W. Zhao, N. Dimov, S. Okada and T. Nishida, J. Electrochem. Soc., 2013, 160, A3077-A3081.

4 X. H. Ma, H. L. Chen and G. Ceder, J. Electrochem. Soc., 2011, 158, A1307-A1312.

5 S. Komaba, C. Takei, T. Nakayama, A. Ogata and N. Yabuuchi, Electrochem. Commun., 2010, 12, 355-358.

6 P. Vassilaras, X. H. Ma, X. Li and G. Ceder, J. Electrochem. Soc., 2013, 160, A207-A211.

7 K. Kubota, S. Kumakura, Y. Yoda, K. Kuroki and S. Komaba, Adv. Energy Mater., 2018, 8, 1703415.

8 C. Delmas, C. Fouassier and P. Hagenmuller, Phys. Rev. B: Condens. Matter Mater. Phys., 1980, 99, 81-85.

9 A. Mendiboure, C. Delmas and P. Hagenmuller, J. Solid State Chem., 1985, 57, 323-331.

10 N. Yabuuchi and S. Komaba, Sci. Technol. Adv. Mater., 2014, 15, 043501.

11 R. J. Clement, P. G. Bruce and C. P. Grey, J. Electrochem. Soc., 2015, 162, A2589-A2604.

12 S. Kumakura, Y. Tahara, K. Kubota, K. Chihara and S. Komaba, Angew. Chem., Int. Ed., 2016, 55, 12760-12763.

13 J.-P. Parant, R. Olazcuaga, M. Devalette, C. Fouassier and P. Hagenmuller, J. Solid State Chem., 1971, 3, 1-11.

14 A. M. Abakumov, A. A. Tsirlin, I. Bakaimi, G. Van Tendeloo and A. Lappas, Chem. Mater., 2014, 26, 3306-3315.

15 J. Billaud, R. J. Clement, A. R. Armstrong, J. CanalesVazquez, P. Rozier, C. P. Grey and P. G. Bruce, J. Am. Chem. Soc., 2014, 136, 17243-17248.

16 M. Shishkin, S. Kumakura, S. Sato, K. Kubota, S. Komaba and H. Sato, Chem. Mater., 2018, 30, 1257-1264.

17 X. Li, X. H. Ma, D. Su, L. Liu, R. Chisnell, S. P. Ong, H. L. Chen, A. Toumar, J. C. Idrobo, Y. C. Lei, J. M. Bai,
F. Wang, J. W. Lynn, Y. S. Lee and G. Ceder, Nat. Mater., 2014, 13, 586-592.

18 X. Chen, Y. C. Wang, K. Wiaderek, X. H. Sang, O. Borkiewicz, K. Chapman, J. LeBeau, J. Lynn and X. Li, Adv. Funct. Mater., 2018, 28, 1805105.

19 T. Y. Ma, G. L. Xu, Y. Li, B. A. Song, X. Q. Zeng, C. C. Su, W. L. Mattis, F. M. Guo, Y. Ren, R. H. Kou, C. J. Sun, S. M. Heald, H. H. Wang, R. Shahbazian-Yassar, J. Jorne, Z. H. Chen and K. Amine, ACS Appl. Energy Mater., 2018, 1, 5735-5745.

20 K. Kubota, M. Miyazaki and S. Komaba, in 228th ECS Meeting, Phoenix, AZ, 2015.

21 F. Izumi and K. Momma, Solid State Phenom., 2007, 130, 1520.

22 K. Momma and F. Izumi, J. Appl. Crystallogr., 2011, 44, 12721276.

23 T. Sato, K. Yoshikawa, W. Zhao, T. Kobayashi, H. B. Rajendra, M. Yonemura and N. Yabuuchi, Energy Mater. Adv., 2021, 2021, 9857563.

24 N. Yabuuchi, H. Yoshida and S. Komaba, Electrochemistry, 2012, 80, 716-719.

25 K. Kubota, I. Ikeuchi, T. Nakayama, C. Takei, N. Yabuuchi, H. Shiiba, M. Nakayama and S. Komaba, J. Phys. Chem. C, 2015, 119, 166-175.

26 S. Doubaji, B. Philippe, I. Saadoune, M. Gorgoi, T. Gustafsson, A. Solhy, M. Valvo, H. Rensmo and K. Edstroom, ChemSusChem, 2016, 9, 97-108.

27 S. Komaba, T. Ishikawa, N. Yabuuchi, W. Murata, A. Ito and Y. Ohsawa, ACS Appl. Mater. Interfaces, 2011, 3, 4165-4168.

28 L. G. Wang, J. J. Wang, X. Y. Zhang, Y. Ren, P. J. Zuo, G. P. Yin and J. Wang, Nano Energy, 2017, 34, 215-223.

29 M. Shishkin and H. Sato, J. Phys. Chem. C, 2021, 125, 15311543.

30 A. J. Toumar, S. P. Ong, W. D. Richards, S. Dacek and G. Ceder, Phys. Rev. Appl., 2015, 4, 064002.

31 Y. D. Kondrashev and A. I. Zaslavskii, Izv. Akad. Nauk SSSR Ser. Fiz., 1951, 15, 179-186.

32 A. R. Armstrong, A. J. Paterson, A. D. Robertson and P. G. Bruce, Chem. Mater., 2002, 14, 710-719.

33 Q. Huang, J. T. Liu, L. Zhang, S. Xu, L. B. Chen, P. Wang, D. G. Ivey and W. F. Wei, Nano Energy, 2018, 44, 336-344.

34 M. H. Han, E. Gonzalo, M. Casas-Cabanas and T. Rojo, J. Power Sources, 2014, 258, 266-271.

35 S. Komaba, N. Yabuuchi, T. Nakayama, A. Ogata, T. Ishikawa and I. Nakai, Inorg. Chem., 2012, 51, 6211-6220.

36 K. Kubota, N. Fujitani, Y. Yoda, K. Kuroki, Y. Tokita and S. Komaba, J. Mater. Chem. A, 2021, 9, 12830-12844.

37 K. Kubota, T. Asari, H. Yoshida, N. Yabuuchi, H. Shiiba, M. Nakayama and S. Komaba, Adv. Funct. Mater., 2016, 26, 6047-6059.

38 L. I. Hill and A. Verbaere, J. Solid State Chem., 2004, 177, 4706-4723. 